\title{
Barriers in Access to Health Care Services among Lesbian, Gay, Bisexual, Transgender (LGBT)
}

\author{
Priya Darshani Giri, Anup Adhikari, Mamata Pradhan, Ishu Yogi, Sudip Khanal
}

\begin{abstract}
Health is one of the fundamental rights of every human being without distinction on any basis. Yet,the Lesbian, Gay, Bisexual, and Transgender population still suffer from prejudice and discrimination in access and use of these serviceswhich place disparities in health status between sexual- and gender-minority and heterosexual individuals. The purpose of this Descriptive cross-sectional study was to assess the barriers in access to health care services among the Lesbian, Gay, Bisexual, and Transgender (LGBT) individuals within the Kathmandu Valley using Semi-structured questionnaires. This study was conducted among 87 LGBT participants including $\mathbf{4 9 . 9 \%}$ Cisgender, $\mathbf{5 0 . 6 \%}$ Transgender,50.6\% heterosexual, $46 \%$ homosexual, and $3.4 \%$ bisexual individuals. Only28.7\% of them faced physical barriersi.e.,toilet $\mathbf{7 6 \%}$ and registration forms $\mathbf{7 6 \%}$, changing room $36 \%$, wards $24 \%$, gender binary queues $20 \%$, and Age of $<21(\mathrm{p}=\mathbf{0 . 0 3 5})$ and Homosexual group $(p=0.021)$ statistically significant with behavioral barriers. However, Age of group $>38(p=0.001)$, respondent with secondary level $(p=0.005)$ and socially open about own sexual orientation and gender identity associated with Psychological barriers.
\end{abstract}

Index Terms-Access, Barriers, Health care services, LGBT

\section{INTRODUCTION}

Lesbian, gay, bisexual, and transgender (LGBT) is an umbrella term, which includes a number of groups: lesbian, gay, bisexual, transgender, queer, questioning, intersex, asexual, allies, two spirits, and pansexual.About $3.5 \%$ Americans identify themselves aslesbian, gay, or bisexual while $0.3 \%$ identify themselves as transgender [1].

Priya DarshaniGiri, Purbanchal University/ Asian College for Advance Studies, Kathmandu, Nepal

Anup Adhikari, General Secretory, Nepal Family Development Foundation, Lalitpur, Nepal

Mamata Praadhan, Department of Nursing, Purbanchal University/ Asian College for Advance Studies ,Kathmandu, Nepal

Ishu Yogi, Department of Nursing, Purbanchal University/ Asian College for Advance Studies, Kathmandu, Nepal

Sudip Khanal, Academician and Statistician, Kathmandu
The facts regarding the situation of LGBT in Nepal are rare; however, there are estimated to be more than 4000,000 people who belong to sexual and gender minorities [2] in Nepal. According to The Williams Institute/BDS survey 2013 done among 1,178 participants from 32 out of 75 districts of Nepal, there were $64.5 \%$ transgender female, $7.1 \%$ transgender males, $22.1 \%$ people were considered as male at birth who identified as gay/bisexual and6.4\% people were assigned female role at birth thatlater identified as lesbian/bisexual [3].

The LGBT community is diverse. What binds them together as social and gender minorities are common experiences of stigma and discrimination, with respect to health care, a long history of discrimination and lack of awareness of health needs by health professionals [4]. Currently, in Nepal, there is a lack of understanding of health and well-being, social exclusion, stigma, and discrimination as experienced by these populations [5].

"The enjoyment of the highest attainable standard of health is one of the fundamental rights of every human being without distinction of race, religion, political belief, economic or social condition"[6].

Yet, there are various factors that prevent an individual from gaining access to health, social care and early year services[7], such as High cost of care, Lack of availability of services, Lack of infrastructure, inadequate resources and health workers' motivation[8], financial barriers, discrimination, lack of cultural competence by providers, health systems barriers and socioeconomic barriers[9]. While sexual and gender minorities have many of the same health concerns as the general population, the LGBT population exceptionally face stigma, discrimination, the provision of substandard care, outright denial of care because of an individual's sexual orientation or gender identity[3,10] reluctance to Disclose Gender Identity, and Other Barriers (Health insurances)[11].

This study was carried out using semi-structured questionnaire through interview method to assess the physical, behavioral and psychological barriers in access to health care services among Lesbian, Gay, Bisexual and Transgender (LGBT) individuals who are currently working in the Blue Diamond Society and its associated organizations within the Kathmandu Valley. 


\section{Barriers in Access to Health Care Services among Lesbian, Gay, Bisexual, Transgender (LGBT)}

\section{METHODOLOGY}

A descriptive cross-sectional study was conducted over the months of June- July 2018 among theLGBT individualswithin Kathmandu Valley. The study included a total of 87 LGBT participants who are currently working in the LGBT organizations within the valley namely Federation of Sexual \& Gender Minorities -Nepal (FSGMN), Blue Diamond Society, ParichayaSamaj, Cruise aids, Pink Triangle Nepal, Our Equal Access and Care Nepal. Census was carried out in the purposively selected organizations. Data was collected through predesigned, pre-tested semi-structured questionnaire through interview.

Research instrument was developed after literature review, consultation with supervisors and subject experts from the FSGMN student forum. Pretesting of the developed tool was done in ParichayaSamaj, Sanepa, Lalitpur and necessary modifications were made to assess the understanding and accuracy of test instrument.

The internal consistency of the Likert scales for behavioral and psychological barriers was tested by calculating Cronbach alpha in SPSS version 22. The obtained value was Cronbach alpha 0.947 which was in excellent range. So, all the developed research instruments were used for data collection. Study was conducted after the approval of research committee of Asian college for Advance Studies (ACAS). Similarly, an official letter was submitted to Blue Diamond Society (BDS) regarding this research work. Consent was taken from participants prior to the study.

LGBT individuals who were not available at the time of data collection were excluded. Collected data was entered into Epi-data software and then transferred to Statistical Package for Social Sciences (SPSS)version 22. Descriptive statistics like frequency, mean,standarddeviation, percentage andKruskal Wallis test and Mann-Whitney U test were used for analysis.

\section{FINDINGS}

This study comprised 87 participants including 75 (86.2\%) biologically born male and 12(13.8\%) biologically born female, mostly (70\%) from the age group 21 to 38 years of age (mean 29.61+8.55). The study had 35(40.2\%) transgender females and $9(10.3 \%)$ transgender males, $40(46.0 \%)$ homosexuals and $3(3.4 \%)$ bisexual participants. However, $56(64.4 \%)$ among the total participants reported to be socially open about their sexual orientation and gender identity and $31(35.6 \%)$ of them are yet to come out. Total $28(32.2 \%)$ had completed secondary level education while only $6(6.9 \%)$ of them were illiterate. (SeeTableI)

Table I. Demographic information of participants

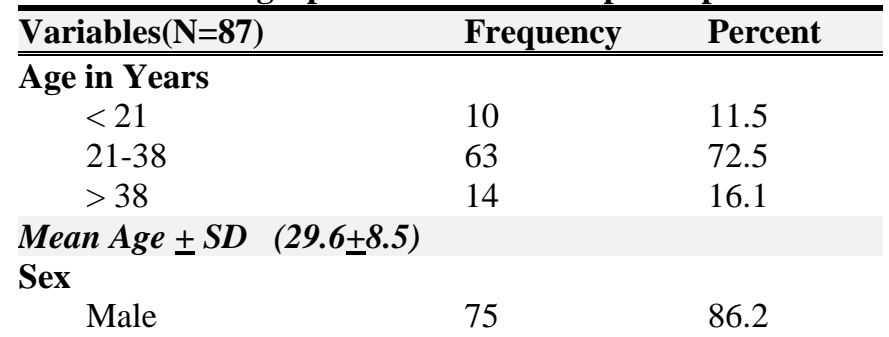

Female

12

Gender identity

Cisgender male

40

Cisgender female

Transgender male

3

Transgender female

9

35

Sexual orientation

$\begin{array}{lll}\text { Heterosexual } & 44 & 50.6 \\ \text { Homosexual } & 40 & 46.0 \\ \text { Bisexual } & 3 & 3.4\end{array}$

Socially open about own sexual orientation and gender identity

\begin{tabular}{lll} 
Yes & 56 & 64.4 \\
$\begin{array}{l}\text { No } \\
\text { el of education }\end{array}$ & 31 & 35.6 \\
Illiterate & 6 & 6.9 \\
Primary & 12 & 13.8 \\
Secondary & 28 & 32.2 \\
Higher secondary & 27 & 31.0 \\
Bachelors and higher & 14 & 16.1 \\
\hline
\end{tabular}

Table II shows that out of 87 participants, only $28.7 \%$ participants faced problems due the physical setting of the health care centers. Most of the problems faced were due to lack of LGBT- friendly settings such as registration forms $(76 \%)$, toilets $(76 \%)$, changing rooms $(36 \%)$, wards $(24 \%)$, arrangement of separated queues of either male or female $(20 \%)$, and procedure rooms $(5.3 \%)$.

Table II. Physical barriersin access to health care services

\begin{tabular}{lcc}
\hline Variables & Frequency & Percent \\
\hline \hline Problems faced & 25 & 28.7 \\
Problems not faced & 62 & 71.3 \\
If yes, types of problems & & \\
faced* \\
lack of LGBT-friendly & & \\
registration forms & 19 & 76 \\
lack of LGBT-friendly toilets & 19 & 76 \\
$\begin{array}{l}\text { Separated arrangement of } \\
\text { only male and female queues }\end{array}$ & 19 & 76 \\
Problems due to lack of \\
$\begin{array}{l}\text { LGBT-friendly changing } \\
\text { rooms }\end{array}$ \\
$\begin{array}{l}\text { Problems due to lack of } \\
\text { LGBT-friendly wards }\end{array}$ \\
$\begin{array}{l}\text { Problems due to lack of } \\
\text { LGBT friendly procedure } \\
\text { rooms }\end{array}$ & \\
\hline
\end{tabular}

*Multiple responses

Out of 87 participants, 58 (66.7\%) participantsadmitted that the health care personnel were friendly and are communicated properly $(68.9 \%)$ and showed respect towards them (66.7\%). Moreover to it, 62 (71.3\%) of the participants accepted that the health care personnel were sensitivetowards their health needs, kept their sexualand gender status confidential $(57.4 \%)$ and accepted to provide care to them regardless of their sexual and gender identity (75.8\%). (SeeTable III) 
Table III. Behavior of Health workers as barriers in access to health care services

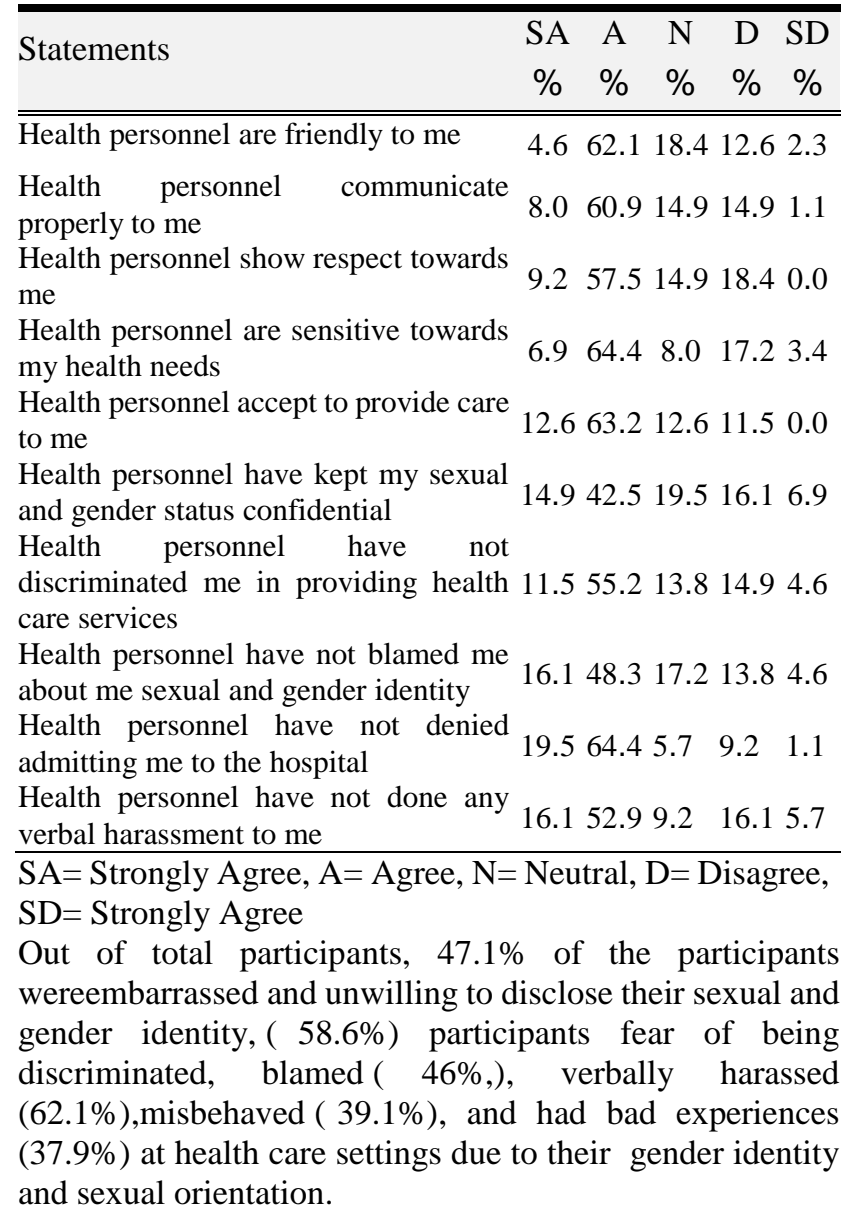

Table IV. Psychological barriersin access to health care services

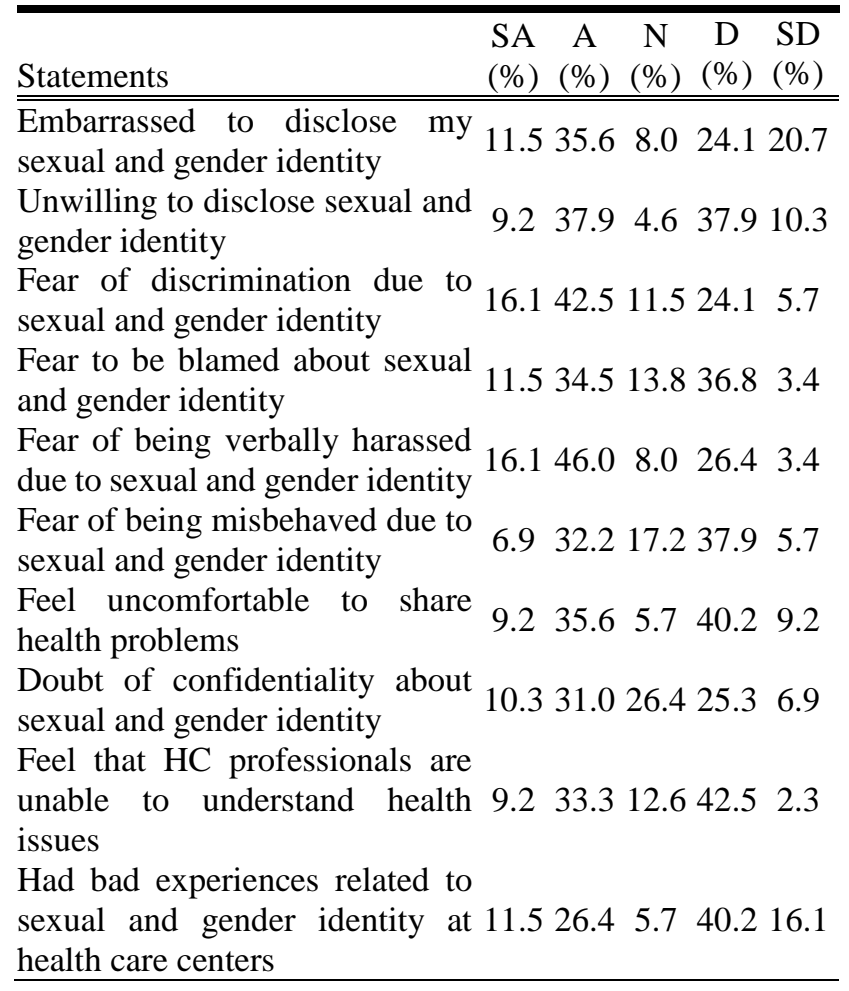

$\mathrm{SA}=$ Strongly Agree, $\mathrm{A}=$ Agree, $\mathrm{N}=$ Neutral, $\mathrm{D}=$ Disagree, $\mathrm{SD}=$ Strongly Agree
A total of $42.5 \%$ participants felt that health care professionals are unable to understand their health issues, and $44.8 \%$ felt uncomfortable to share health problems and only $41.3 \%$ of them doubt that their sexual and gender identity would be kept confidential. (See Table IV).

Table V. Association between socio-demographic variables and behavioral barriers

\begin{tabular}{|c|c|c|c|c|}
\hline \multicolumn{5}{|c|}{ Kruskal Wallis Test } \\
\hline Factors & Median & $\overline{\mathrm{H}}$ & $\overline{\mathrm{Df}}$ & $\mathrm{p}$ \\
\hline Age in years & & 6.71 & 2 & \\
\hline$<21$ & 59.4 & & & $0.035^{*}$ \\
\hline $21-38$ & 44.4 & & & \\
\hline$>38$ & 33.6 & & & \\
\hline Gender identity & & 6.12 & 3 & \\
\hline Cisgender male & 50.5 & & & 0.107 \\
\hline Cisgender female & 50.2 & & & \\
\hline Transgender male & 32.3 & & & \\
\hline $\begin{array}{l}\text { Transgender } \\
\text { female }\end{array}$ & 39.1 & & & \\
\hline Sexual orientation & & 7.68 & 2 & \\
\hline Heterosexual & 37.7 & & & \\
\hline Homosexual & 48.9 & & & $0.021 *$ \\
\hline Bisexual & 70.7 & & & \\
\hline Level of education & & 3.47 & & \\
\hline Illiterate & 53.1 & & & \\
\hline Primary & 51.9 & & & \\
\hline Secondary & 39.0 & & & 0.481 \\
\hline Higher secondary & 45.6 & & & \\
\hline $\begin{array}{l}\text { Bachelors and } \\
\text { higher }\end{array}$ & 40.3 & & & \\
\hline \multicolumn{5}{|c|}{ Mann-Whitney U Test } \\
\hline & Median & $\mathrm{U}$ & & \\
\hline Sex & & 363.5 & & 0.284 \\
\hline Male & 45.2 & & & \\
\hline Female & 36.8 & & & \\
\hline \multicolumn{2}{|c|}{$\begin{array}{l}\text { Socially open about own sexual } \\
\text { orientation and gender identity }\end{array}$} & 853.5 & & \\
\hline Yes & $43.7^{\circ}$ & & & 0.897 \\
\hline No & 44.5 & & & \\
\hline
\end{tabular}

The table $\mathrm{V}$ shows that Behavioral barrier is strongly associated with age groups of $<21$ years $(p=0.035)$ and sexual orientation at homosexual group $(p=0.021)$. However, Behavioral barrier is not statistically significant with gender identity, level of education, biological sex and socially open about own sexual orientation and gender identity.

Table VI.Association between sociodemographic variables and psychological barriers

\begin{tabular}{|c|c|c|c|}
\hline \multicolumn{4}{|c|}{ Kruskal Wallis Test } \\
\hline Factors & Median & $\mathrm{H}$ & df p \\
\hline Age in years & & 17.78 & 2 \\
\hline$<21$ & 53.6 & & \\
\hline $21-38$ & 48.3 & & \\
\hline$>38$ & 23.2 & & $0.001 *$ \\
\hline Gender identity & & 5.59 & 3 \\
\hline Cisgender male & 49.2 & & 0.134 \\
\hline
\end{tabular}




\section{Barriers in Access to Health Care Services among Lesbian, Gay, Bisexual, Transgender (LGBT)}

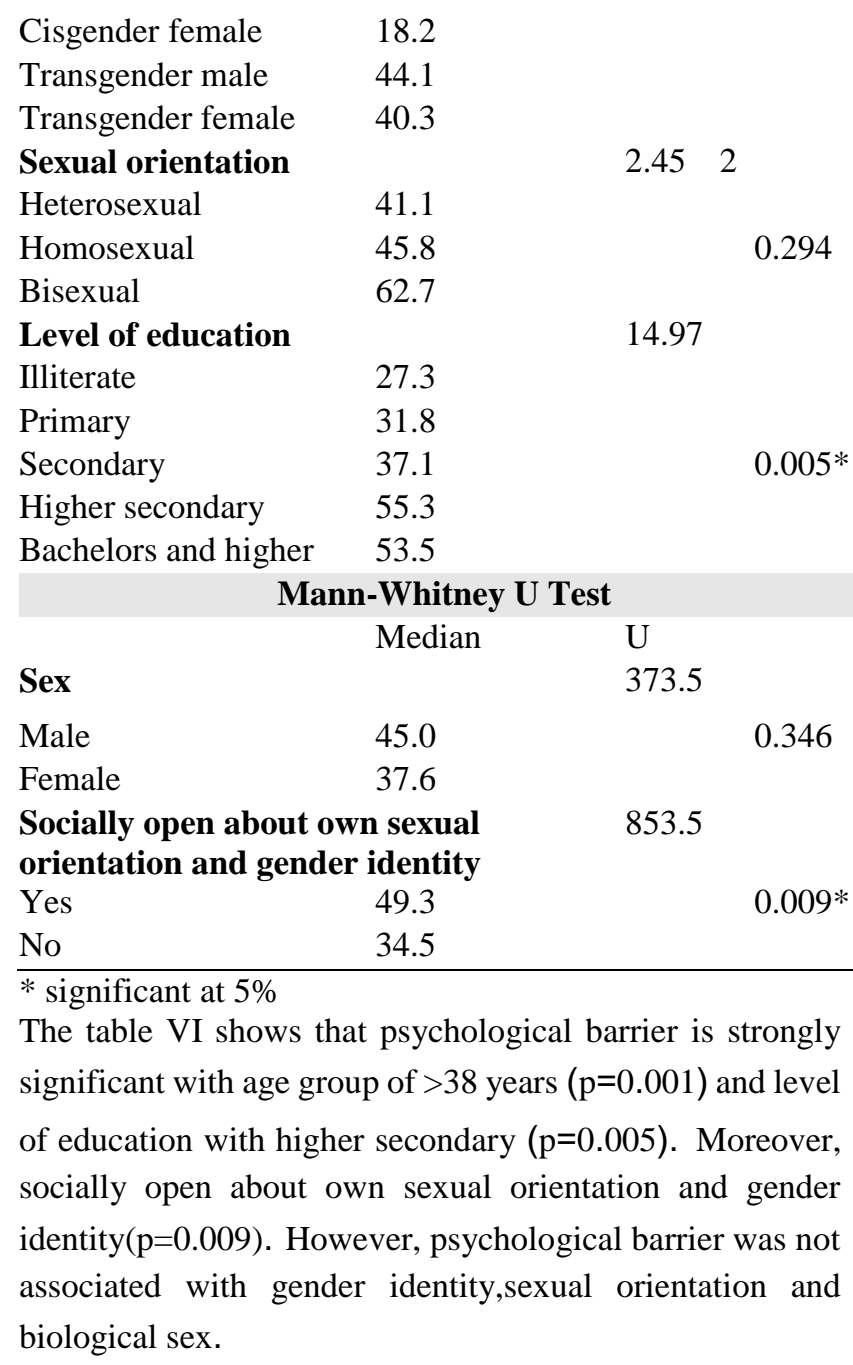

\section{DISCUSSION}

The socio demographic information of the current study showed that that out of 87 participants, more than $70 \%$ of them were from the age group 21 to 38 years of age. The mean age of the participants was 29.6years. Similar finding is found in a recent cross sectional study in Nepal conducted among 232 Male to Female(MtF) transgender persons shows that the median age of the participants was 25 years and most of the respondents $(56.5 \%)$ were aged 25 years and above[12]. Nearly half (49.4\%) of the participants were Cisgender while $50.6 \%$ of them identify themselves as Transgender individuals. Likewise, half of the total participants (50.6\%) were heterosexual, and 46 percent of them report their sexual orientation to be homosexual and only few (3.4\%) of the participants say that they are. Bisexual. In another similar study about 3.5\% Americans identify themselves as lesbian, gay, or bisexual while $0.3 \%$ identify themselves as transgender [ 1]. Regarding the status of coming out, the study findings show that more than half $(64.4 \%)$ among the total participants reported to have come out about their sexual orientation and gender identity in the society and friends. However, more than one fourth $(35.6 \%)$ of them are yet to come out. The study findings also indicates that most of the participantshad completedsecondary (32.2\%) and higher secondary $(31 \%)$ level of education. As stated in a report on the Nepal National LGBTI Community Dialogue held in Kathmandu in April 2014, Some LGBT students dropped out of school due to bullying and harassment [4]. In the study of 232 transgender females in Nepal, more than half $(57.3 \%)$ of the total sample had a secondary or higher level of education [12].

The types of physical barriers identified in the study are problems due to physical setting of the health facility mainly barriers due to lack of LGBT- friendly registration forms (76\%), toilets (76\%) and the system of arrangement of queues in either male of female $(20 \%)$ which causes problems to these individuals while accessing the health care service center. Similarly, nearly half $(47.4 \%)$ of the problems faced by the LGBT individuals was due to lack of LGBT friendly changing rooms. Similar findings are found in a qualitative study among Lesbians of Nepal, theparticipants commonly reported that it is difficult to make an appointment with the doctors because the disclosure of male or female identity is required in most cases. In addition, they also argued that they did not find it comfortable to be in a male or female ward. It has often made it difficult for them to decide whether to get admitted or not [13].

Similarly, behavior of health care provider was also identified as the barriers in access to health care. A total of $63.2 \%$ participants experienced lowlevels of behavioral barriers in access to health care services. Significant associations were also seen between theparticipants' age, sexual orientation, gender identity with how the health care providers behave with the client from sexual and gender minority group. The study conducted by Williams Institute/BDS across 32 districts of the country also presents that over 60 percent of the participants reported experiencing at least one incident related to verbal harassment, physical abuse and denial of service in health care settings [3]. Similar kind of finding was also seen in the report of the National Transgender Discrimination Survey of transgender individuals. It was found that $19 \%$ of the sample reported being refused medical care due to their transgender or gender non-conforming status. Survey participants also reported that when they were sick or injured, many postponed medical care due to discrimination $(28 \%)$ or inability to afford it $(48 \%)$ which clearly indicates discrimination in health care and poor health outcomes [14]. Systematic review conducted using PubMed, Cochrane, SciELO, and LILACS, considering the period from 2004 to 2014 reveals that the homosexual 
population have difficulties of access to health services as a result of heteronormative attitudes imposed by health professionals [15].

Apart from the physical and behavioral barriers, psychological barriers also play vital role in access to health care among LGBT population. The psychological barriers were found to be high in $52.9 \%$ study participants out of 87. Study participantsexperienced ahigh level of psychological barrier. The study findings reveal that 10 out of 87 of the study participants confessed that they did not go for regular health checkups due to the fear of being misbehaved by the health care personnel. About $60 \%$ of the participants stated 'experience of fear of being misbehaved by health care staff' as the main reason for postponing their health care treatment. Similarly, $42.5 \%$ agreed that they had fear of being discriminated on the basis of their sexual orientation and gender identity. As a result, LGB persons' previous negative experiences with the health care system or perceptions of discrimination in the system may cause them to delay seeking health care [16].

\section{ACKNOWLEDGMENTS}

We thank all the study participants who have contributed to this study.We are also grateful to Asian college for advance studies, the Federation of Sexual \& Gender Minorities -Nepal (FSGMN), Blue Diamond Society, ParichayaSamaj, Cruise aids, Pink Triangle Nepal, Our Equal Access and Care Nepal. Similarly,our vote of thanks goes to Nepal Family Development Foundationfor support in data management, analysis and interpretation and report writing.

\section{REFERENCES}

[1] Hafeez H, Zeshan M, Tahir MA, Jahan N, Naveed S. Health Care Disparities Among Lesbian, Gay, Bisexual, and Transgender Youth: A Literature Review. Cureus[Internet]. 2017;9(4). Available from:

http://www.cureus.com/articles/6744-health-care-disparities-amon g-lesbian-gay-bisexual-and-transgender-youth-a-literature-review

[2] Mahato R. The Movement for Human Rights for Sexual and Gender Minorities in Nepal:The Beginning,.Int Dev Community Environ. 2017; 2001-15.

[3] UNDP, Williams Institute. Surveying Nepal's sexual and gender minorities: An inclusive approach. 2014; Available from: http://www.asia-pacific.undp.org/content/dam/rbap/docs/Research $\&$

Publications/hiv_aids/rbap-hhd-2014-surveying-nepals-sexual-andgender-minorities.pdf

[4] Ard KL, Makadon HJ. Improving the HealthCare of LGBT People : Understanding and Eliminating Health Disparities. 2012; 1-12. Available from:

https://www.lgbthealtheducation.org/publication/improving-the-he alth-care-of-lesbian-gay-bisexual-and-transgender-lgbt-people-und erstanding-and-eliminating-health-disparities/

[5] Regmi PR, Van Teijlingen E. Importance of health and social care research into gender and sexual minority populations in Nepal. Asia-Pacific J Public Heal. 2015;27(8):806-8.

[6] WHO | Health is a fundamental human right. WHO [Internet]. 2017 [cited 2019 Mar 3]; Available from:

https://www.who.int/mediacentre/news/statements/fundamental-hu man-right/en/

[7] Academies I of M of the N. Committee on Lesbian, Gay, Bisexual, and Transgender Health Issues and Research Gaps and Opportunities. Institute of Medicine of the National Academies.
[8] Chiang C, Labeeb SA, Higuchi M, Mohamed AG, Aoyama A, Paper O. Barriers to the use of basic health services among women in rural southern Egypt (Upper Egypt). Nagoya J Med Sci. 2013;75(3/4):225-31.

[9] Safer JD, Coleman E, Feldman J, Garofalo R, Hembree W, Sevelius J. HHS Public Access. 2017;23(2):168-71.

[10] Ranji U, Beamesderfer A. Health and Access to Care and Coverage for Lesbian, Gay, Bisexual, and Transgender Individuals in the US . Issue Brief The LGBT Community. 2014;1-33. Available from http://files.kff.org/attachment/issue-brief-health-and-access-to-care -and-coverage-for-lgbt-individuals-in-the-u-s-2

[11]OHTN Rapid Response Service. Facilitators and barriers to health care for lesbian, gay and bisexual (LGB) people. Rapid Rev [Internet]. 2014;79(March). Available from: http://www.ohtn.on.ca/Pages/Knowledge-Exchange/Rapid-Respon ses/Documents/RR79.pdf

[12] Bhatta DN. HIV-related sexual risk behaviors among male-to-female transgender people in Nepal. Int J Infect Dis [Internet]. International Society for Infectious Diseases; 2014; 22:11-5. Available from: http://dx.doi.org/10.1016/j.ijid.2014.01.002

[13] Pathak R, Regmi PR, Pant PR, Simkhada P, Douglas F, Stephens J. Gender Identity: Challenges to Accessing Social and Health Care Services for Lesbians in Nepal. Glob J Health Sci [Internet]. 2010;2(2):207-14. Available from:https://ezproxy.library.nyu.edu/login?url?url=http://search.pr oquest.com/docview/822026291? accountid=33843

[14] Grant JM, Mottet La, Tanis J, Harrison J, Herman JL, Keisling M. Injustice at every turn: A report of the National Transgender Discrimination Survey. Natl Cent Transgender Equal [Internet]. 2010;5:23. Available from: http://transequality.org/PDFs/NTDS Report.pdf\%5Cnhttp://2fww w.thetaskforce.org/downloads/resources and tools/ntds report on health.pdf

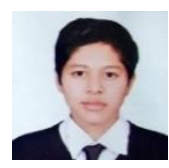

Priya DarshaniGiri is a student of Bachelor in Public Health at Asian College for advance studies, Purbanchal University, Nepal.

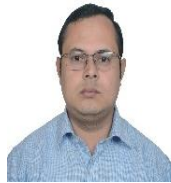

Anup Adhikari isa General secretory of Nepal Family Development Foundation (NFDF). He had completed master's degree in population studies from Central Department of Population Studies. He had published many research articles in national and international journals. He had more than 8 years of research-based project and working experience in Data management and analysis by using various statistical software. Currently he is working on TyVAC project as a team leader and Editor at yaunik.com online magazine.

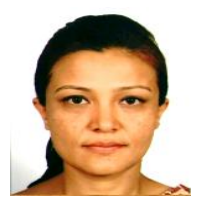

Mamata Pradhanisworking as Co-ordinator at Asian College for Advance Studies, Satdobato, Lalitpur. She had completed her Bachelor Degree in Nursing from TUIOM Lalitpur Nursing Campus, Sanepa, and Master Degree in Public Health from Sam Higginbottom Institute of Agriculture, Technology\& Sciences Aallahabad, India. She has more than 15 years' experience in Clinical Nursing and academic. 
Barriers in Access to Health Care Services among Lesbian, Gay, Bisexual, Transgender (LGBT)

Ishu Yogiis working as Lecturer at Asian College for Advance Studies, Satdobato, Lalitpur. She had completed Masters in Nursing (MN) in Advance Adult Nursing from T.U.I.O.M

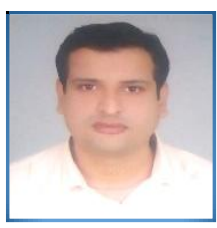

Sudip Khanalis working as a Statistician and Academician. He hadcompleted Msc.Statistics from Central Department of Statistics. He had more then 10 years of teaching and more than 2 years working experience in Data management and analysis by using various statistical software. Currently he is working in Nepal Family development Foundation as a trainer on Data management and Analysis. 